\title{
Comparison Between Balloon-Assisted and Stent-Assisted Technique for Treatment of Unruptured Internal Carotid Artery Aneurysms
}

\author{
Keun Young Park, MD ${ }^{2,3}$, Byung Moon Kim, MD ${ }^{1,3}$, Dong Joon Kim, MD ${ }^{1,3}$
}

Purpose: To compare clinical and angiographic outcomes between balloon-assisted (BAC) and stentassisted coiling for internal carotid artery unruptured aneurysms (ICA-UA).

Materials and Methods: A total of 227 ICA-UA in 190 patients were treated with BAC (120 patients, 141 ICA-UA) or SAC (70 patients, 86 ICA-UA. We compared characteristics of patients and ICA-UA, and clinical and angiographic outcomes between groups.

Results: Aneurysm size and neck diameter were greater for SAC than in BAC, but aneurysm volume and coil packing density were not different between groups. Immediate angiographic occlusion grade was better for BAC than for SAC. Periprocedural thromboembolic events were more frequent during SAC (11.6\%) than BAC (2.4\%) per aneurysm, but hemorrhagic events were the opposite $(2.4 \%$ for BAC and none for SAC per aneurysm) $(p<0.05)$. At discharge, treatment-related morbi-mortality rates were $1.6 \%$ for BAC and $1.4 \%$ per patient for SAC. At clinical follow-up (BAC, 118 patients [98.3\%] for a mean of 48.4 months; SAC, 69 patients [98.6\%], for a mean of 37.4 months), 1 additional treatment-related infarction occurred during SAC, resulting in a modified Rankin scale score of 4. Thus, overall treatment-related morbi-mortality rates were $1.7 \%$ in BAC and $2.9 \%$ in SAC. At imaging follow-up (BAC, 135 aneurysms [95.7\%] for 28.3 months; SAC, 81 aneurysms [94.1\%] for 23.9 months), BAC and SAC showed stable or improved occlusion in $94.1 \%$ and $95.0 \%$, minor recurrence in $4.4 \%$ and $2.5 \%$, and major recurrence in $1.5 \%$ and $2.5 \%$, respectively.

Conclusion: Both BAC and SAC were safe and effective techniques for ICA-UA. There were no differences in morbi-mortality and recurrence rates between groups.

Key Words : Aneurysm; Internal carotid artery; Coil embolization; Balloon; Stent

Departments of ${ }^{1}$ Radiology and ${ }^{2}$ Neurosurgery, ${ }^{3}$ Severance Hospital Stroke Center, Yonsei University College of Medicine, Seoul, Korea Received August 1, 2016; accepted after revision August 16, 2016.

Correspondence to: Byung Moon Kim, MD, PhD, Interventional Neuroradiology, Department of Radiology, Severance Hospital Stroke Center, Yonsei University College of Medicine, 50 Yonsei-ro, Seodaemun-gu, Seoul 03722, Korea.

Tel. 82.10.9054.0551 Fax. 82.2.393.3035

E-mail: bmoon21@hanmail.net

This is an Open Access article distributed under the terms of the Creative Commons Attribution Non-Commercial License (http://creativecommons.org/licenses/by-nc/3.0) which permits unrestricted non-commercial use, distribution, and reproduction in any medium, provided the original work is properly cited. 


\section{Keun Young Park, et al.}

Endovascular coiling is the preferred treatment for ruptured or unruptured intracranial aneurysms [1-4]. For treatment of internal carotid artery unruptured aneurysms (ICA-UA), coiling is the more favored treatment. On the other hand, balloon and stent are representative of assistant devices for wide-neck aneurysm coiling [5-14]. Both devices were more frequently used for ICA-UA, because ICA is the largest of the intracranial arteries and is easy to navigate. Each device has its own strengths and drawbacks in coiling of ICA-UA [9-14]. To date, there were no studies comparing balloon-assisted (BAC) and stent-assisted coiling for the treatment of ICA-UA. The purpose of this study was to compare clinical and angiographic outcomes between BAC and SAC for IAC-UA.

\section{PATIENTS AND METHODS}

All ICA-UA that underwent BAC or SAC were identified from prospectively maintained neurointerventional databases in single academic tertiary referral hospitals between January 2010 and July 2015. The inclusion period was determined such that at least 1year clinical follow-up was available for patients at the latest out-patient or telephone follow-up. The institutional review board approved this retrospective study with a waiver of informed consent for study inclusion. All relevant clinical and imaging data were obtained from electronic medical charts, a picture archive system, and a prospectively registered neurointerventional database. The clinical and angiographic outcomes were retrospectively analyzed.

\section{Coiling procedure}

Procedural details were previously described in the literature $[16,17]$. Briefly, all patients with unruptured aneurysms who scheduled coil embolization received dual antiplatelet premedication (aspirin $100 \mathrm{mg}$ and clopidogrel $75 \mathrm{mg}$ ) for at least 5 days. Dual antiplatelet medication was maintained for at least 3 months and then was changed to aspirin monotherapy for patients receiving SAC. Dual antiplatelet medication was stopped for patients receiving BAC. After introduction of a guiding catheter, a bolus of heparin $3000 \mathrm{IU}$ was injected and then heparin $1000 \mathrm{IU}$ was given as a booster every hour. A 6-French shuttle guiding sheath was placed in the relevant internal carotid artery.

The adjunctive balloons used in this study were Hyperform/Hyperglide (Covidien, Irvine, California) and Scepter C balloons (Microvention, Tustin, California). The stents used in this study included
Enterprise (Codman Neurovascular, Ratham, Massachusetts), Neuroform (Stryker Neurovascular, Fremont, California), and Solitaire AB (Covidien, Irvine, California) stents. It depended on the operator's preference to choose which type of treatment, BAC or SAC.

\section{Outcome measures}

Treatment-related morbidity was defined as the development of any new neurological deficit due to treatment-related complications that were still present at discharge. Treatment-related mortality was defined when the patient died from treatment-related complications during clinical follow-up. The clinical outcome at the latest follow-up was defined as the final outcome. If the latest clinical follow-up was more than 3 months at the point of the analysis of this study, a telephone interview was obtained to determine the patient's clinical status.

Immediate post-coiling angiographic outcome was analyzed according to Raymond's grade, where class 1 means complete obliteration; class 2 means a residual neck; and class 3 means a residual aneurysm [15].

Imaging follow-up was conducted with MR angiography or catheter angiography. Follow-up angiographic outcome was also analyzed to Raymond's grade [15] and was additionally classified into 3 categories: improved/stable, minor recurrence when the recurred aneurysm didn't require re-treatment and major recurrence when the recurred aneurysm required retreatment. The need for re-treatment was determined based on discussion among 2 neurointerventionists and 3 vascular neurosurgeons in a weekly neurovascular conference.

\section{Statistical analysis}

Statistical analysis performed using IBM SPSS version 20. Each continuous variable was presented with a mean $\pm \mathrm{SD}$ and each categorical variable was analyzed with an incidence and \%. The unpaired t-test was used for continuous variables with a normal distribution and the Mann-Whitney U test was used for continuous variables without a normal distribution. The $x^{2}$ test was used for categorical variables. Statistical significance was determined as $\mathrm{p}$-value $<.05$ within a $95 \%$ confidence interval.

\section{RESULTS}

A total of 227 ICA-UA in 190 patients were treated with BAC (120 patients, 141 ICA-UA) or SAC (70 
patients, 86 ICA-UA). Five ICA-UA were initially BAC but converted to SAC. Table 1 summarizes the characteristics of patients and IC-UA, and immediate clinical and angiographic outcomes. There were no differences in age and gender between groups. Aneurysm size and neck diameter were greater in SAC than in BAC, but aneurysm volume and coil packing density were not different between groups. Immediate angiographic occlusion grade was better in BAC than in SAC. Periprocedural thromboembolic events were more frequent in SAC (11.6\%) than in BAC $(2.4 \%)$, but hemorrhagic events were the opposite $(2.4 \%$ for BAC and none for SAC) $(\mathrm{p}<0.05)$. At discharge, treatmentrelated morbi-mortality rates were $1.0 \%$ in BAC and $0.5 \%$ in SAC.

Table 2 summarizes clinical and angiographic follow- up results. At clinical follow-up (BAC, 118 patients [98.3\%] for 48.4 months; SAC, 69 patients [98.6\%], for 37.4 months), 1 additional treatment-related infarction occurred in SAC, resulting in a modified Rankin scale score of 4 . Thus, overall treatment-related morbimortality rates were $1.7 \%$ in BAC and $2.9 \%$ in SAC. At imaging follow-up (BAC, 135 aneurysms [95.7\%] for 28.3 months; SAC, 81 aneurysms [94.1\%] for 23.9 months) with MR angiography $(\mathrm{n}=149)$ or catheter angiography $(\mathrm{n}=67), \mathrm{BAC}$ and SAC showed stable or improved occlusion in $94.1 \%$ and $95.0 \%$, minor recurrence in $4.4 \%$ and $2.5 \%$, and major recurrence in $1.5 \%$ and $2.5 \%$, respectively. Table 3 summarizes treatment-related symptomatic complications during the procedure and follow-up periods.

Table 1. Characteristics of Patients and Aneurysms and Immediate Clinical and Angiographic Outcomes

\begin{tabular}{|c|c|c|c|c|}
\hline & Total & BAC & SAC & $\mathrm{P}$ \\
\hline Patient, n (\%) & 190 & 120 & 70 & \\
\hline Age, mean years (SD) & $54.4 \pm 9.9$ & $53.7 \pm 9.8$ & $55.6 \pm 9.9$ & NS \\
\hline Female & $164(86.3 \%)$ & 104 & 60 & NS \\
\hline No, of aneurysms & 227 & $141(62.1 \%)$ & $86(37.9 \%)$ & \\
\hline Location at ICA & & & & NS \\
\hline Hypophyseal-ophthalmic-paraclinoid, & 167 (73.6\%) & $99(70.2 \%)$ & $68(79.1 \%)$ & \\
\hline Pcom & $39(17.2 \%)$ & $26(18.4 \%)$ & $13(15.1 \%)$ & \\
\hline AChoA & $12(5.3 \%)$ & $12(8.5 \%)$ & 0 & \\
\hline ICA bifurcation & $9(3.9 \%)$ & $4(2.8 \%)$ & $5(5.8 \%)$ & \\
\hline Dome diameter, mm & $5.0 \pm 1.9$ & $4.8 \pm 2.1$ & $5.6 \pm 2.0$ & 0.01 \\
\hline Neck diameter, mm & $3.7 \pm 1.3$ & $3.3 \pm 1.0$ & $4.4 \pm 1.5$ & $<0.01$ \\
\hline Dome-to-Neck ratio & $1.1 \pm 0.4$ & $1.2 \pm 0.4$ & $0.9 \pm 0.4$ & $<0.01$ \\
\hline Sac volume, mm3 & $51.2 \pm 62.6$ & $53.7 \pm 0.8$ & $56.5 \pm 51.8$ & NS \\
\hline Packing density (\%) & $37.4 \pm 13.9$ & $37.5 \pm 12.9$ & $37.3 \pm 15.0$ & NS \\
\hline Immediate Raymond grade & & & & 0.022 \\
\hline 1 & $114(50.2 \%)$ & $73(51.8 \%)$ & $41(47.7 \%)$ & \\
\hline 2 & $81(35.7 \%)$ & $55(39.0 \%)$ & $26(30.2 \%)$ & \\
\hline 3 & $32(14.1 \%)$ & $13(9.2 \%)$ & $19(22.1 \%)$ & \\
\hline Periprocedural events ( $\mathrm{n}=227$ ) & & & & 0.018 \\
\hline Any thromboembolic & $13(5.7 \%)$ & $3(2.4 \%)$ & $10(11.6 \%)$ & \\
\hline Any hemorrhagic & $3(1.3 \%)$ & $3(2.4 \%)$ & 0 & \\
\hline $\begin{array}{l}\text { Treatment-related morbidity and mortality } \\
\text { at discharge }(n=190)\end{array}$ & $3(1.6 \%)$ & $2(1.6 \%)$ & $1(1.4 \%)$ & NS \\
\hline
\end{tabular}

$\mathrm{BAC}=$ balloon-assisted coiling, SAC = stent-assisted coiling, ICA = internal carotid artery, Pcom = posterior communicating artery, AchoA = anterior choroidal artery, NS = not significant. 


\section{Keun Young Park, et al.}

\section{DISCUSSION}

In this study, both BAC and SAC were safe and effective techniques for ICA-UA. Treatment-related morbidity and mortality rates during periprocedural and follow-up periods were very low without a significant difference between groups. Furthermore, recurrence rates were also very low in both groups without a significant difference between groups.

Both balloon and stent are representative of assistant devices for wide-neck aneurysm coiling [5-14]. Although each device has its own strengths and drawbacks in coiling of ICA-UA, each device was frequently used for ICA-UA because ICA is the largest of the intracranial arteries and is easy to navigate. However, to date, there exists no study in the literature to compare outcomes between BAC and SAC for coiling of ICA-UA. This is, to our knowledge, the first study to compare BAC and SAC selectively for ICAUA coiling for a relatively large number of subjects.

In this study, almost all patients and ICA-UA underwent clinical and imaging follow-up. The recurrence rate is quite lower than reported in the literature. Furthermore, a majority of ICA-UAs showed an improving occlusion grade for both groups (Table 2). This is likely due to most ICA-UAs being small (mean aneurysm size, $5.0 \mathrm{~mm}$ ). Another explanation is that most ICA-UAs are of the side-wall type, except for ICA-UAs at the Pcom origin and ICA bifurcation, which was responsible for only $21 \%$ of all ICA-UAs.

With respect to treatment-related complications, it is noteworthy that there was a significant difference in the type of complications between BAC and SAC. Treatment-related thromboembolic events were more frequent for SAC, whereas treatment-related hemorrhagic events were more common for BAC (Table 1). Furthermore, the 2 symptomatic complications in $\mathrm{BAC}$ were due to hemorrhagic one during the periprocedural period, whereas the 2 symptomatic complications in SAC were both ischemic. One of the 2 ischemic complications occurred during periprocedural and the other occurred 18 months after the treatment (Table 3).

This study has some limitations inherent to its retrospective nature. Clinical outcome cannot be

Table 2. Follow-up Clinical and Angiographic Outcomes

\begin{tabular}{|c|c|c|c|c|}
\hline & Total & BAC & SAC & $\mathrm{P}$ \\
\hline Clinical f-u, n (\%) & 187 (98.4\%) & $118(98.3 \%)$ & $69(98.6 \%)$ & NS \\
\hline Clinical f-u period, months & $44.3 \pm 18.9$ & $48.4 \pm 17.8$ & $37.4 \pm 19.1$ & $<0.001$ \\
\hline $\begin{array}{l}\text { Symptomatic thromboembolic, periprocedural } \\
\text { and f-u period }\end{array}$ & $2(1.1 \%)$ & 0 & $2(2.9 \%)$ & NS \\
\hline $\begin{array}{l}\text { Symptomatic hemorrhagic, } \\
\text { periprocedural and f-u period }\end{array}$ & $2(1.1 \%)$ & $2(1.7 \%)$ & 0 & NS \\
\hline $\begin{array}{l}\text { Treatment-related morbidity and mortality at the } \\
\text { latest } f-u\end{array}$ & $4(2.2 \%)$ & $2(1.7 \%)$ & $2(2.9 \%)$ & NS \\
\hline Imaging $f-u(n=227)$ & $216(95.2 \%)$ & $135(95.7 \%)$ & $81(94.1 \%)$ & NS \\
\hline Imaging f-u period, mean $\pm S D$, months & $26.6 \pm 14.9$ & $28.3 \pm 15.9$ & $23.9 \pm 12.6$ & 0.028 \\
\hline Fu occlusion grade & & & & 0.009 \\
\hline Raymond 1 & $174(80.6 \%)$ & $106(78.5 \%)$ & $68(83.9 \%)$ & \\
\hline 2 & $32(14.8 \%)$ & $26(19.3 \%)$ & $6(7.4 \%)$ & \\
\hline 3 & $10(4.6 \%)$ & $3(2.2 \%)$ & $7(8.6 \%)$ & \\
\hline Imaging fu results & & & & NS \\
\hline Stable or improved & 204 (94.4\%) & 127 (94.1\%) & 77 (95.0\%) & \\
\hline Minor recurrence & $8(3.7 \%)$ & $6(4.4 \%)$ & $2(2.5 \%)$ & \\
\hline Major recurrence & $4(1.9 \%)$ & $2(1.5 \%)$ & $2(2.5 \%)$ & \\
\hline
\end{tabular}

BAC = balloon-assisted coiling, SAC = stent-assisted coiling, ICA = internal carotid artery, Pcom = posterior communicating artery, AchoA = anterior choroidal artery, NS = not significant, $F-u=$ follow-up 
Table 3. Treatment-related Symptomatic Complications During the Procedure and follow-up Periods

\begin{tabular}{|c|c|c|c|c|c|c|c|}
\hline No. & Sex/Age & Location & $\begin{array}{l}\text { Dome size, } \\
\qquad(\mathrm{mm})\end{array}$ & Tx & $\begin{array}{l}\text { Device used, } \\
\text { size }(\mathrm{mm})\end{array}$ & Treatment-related symptomatic complications & F-u mRS \\
\hline 1 & $\mathrm{M} / 44$ & ICA paraclinoid & 11.5 & $\mathrm{BAC}$ & Scepter-C, 4/10 & $\begin{array}{l}\text { Aneurysm rupture } 8 \text { hours after uneventful } \\
\text { BAC and full wake-up }\end{array}$ & 3 \\
\hline 2 & $\mathrm{~F} / 70$ & ICA paraclinoid & 4.5 & BAC & Secpter-XC, 4/11 & ICA rupture during $\mathrm{BAC}$ & 6 \\
\hline 3 & $\mathrm{~F} / 67$ & ICA Pcom & 9.0 & SAC & Enterprise, $4.5 / 28$ & Ipsilateral MCA infarction 2 days after SAC & 4 \\
\hline 4 & $\mathrm{~F} / 65$ & ICA Pcom & 4.3 & SAC & Enterprise, $4.5 / 22$ & Ipsilateral MCA infarction 18 months after SAC & 4 \\
\hline
\end{tabular}

$\mathrm{Tx}=$ treatment type, $\mathrm{F}-\mathrm{u}=$ follow-up, $\mathrm{mRS}=$ modified Rankin scale core, $\mathrm{BAC}=$ balloon-assisted coiling, $\mathrm{SAC}=\mathrm{stent}-\mathrm{assisted}$ coiling, ICA = internal carotid artery, Pcom = posterior communicating artery.

compared at the same time, that is, at 3 months or at 12 months. The majority of imaging follow-up was conducted with MR angiography, which may potentially decrease the recurrence rate, especially in SAC. However, the results of this study may provide neurointerventionalists with helpful information regarding their daily practice in that this study was first to compare BAC and SAC for treatment specifically of ICA-UAs, in which both types of coiling techniques are frequently used. In addition, because $98.4 \%$ of the patients were clinically followed-up for a mean of 44 months and $95.2 \%$ of ICA-UAs received imaging follow-up for a mean of 26 months, the results of this study may be reliable, even though they are retrospective.

\section{CONCLUSION}

Both BAC and SAC were safe and effective techniques for ICA-UA. There were no differences in morbi-mortality and recurrence rates between groups.

\section{References}

1. Molyneux AJ, Kerr RS, Yu LM, Clarke M, Sneade M, Yarnold JA, Sandercock P; International Subarachnoid Aneurysm Trial (ISAT) Collaborative Group. International subarachnoid aneurysm trial (ISAT) of neurosurgical clipping versus endovascular coiling in 2143 patients with ruptured intracranial aneurysms: a randomised comparison of effects on survival, dependency, seizures, rebleeding, subgroups, and aneurysm occlusion. Lancet 2005;366:809-817

2. Ryttlefors M, Enblad P, Kerr RS, Molyneux AJ. International subarachnoid aneurysm trial of neurosurgical clipping versus endovascular coiling: subgroup analysis of 278 elderly patients. Stroke 2008;39:2720-2726

3. Lanzino G, Murad MH, d'Urso PI, Rabinstein AA. Coil embolization versus clipping for ruptured intracranial aneurysms: a metaanalysis of prospective controlled published studies. AJNR Am J Neuroradiol 2013;34:1764-1768
4. Raftopoulos C, Mathurin P, Boscherini D, Billa RF, Van Boven M, Hantson P. Prospective analysis of aneurysm treatment in a series of 103 consecutive patients when endovascular embolization is considered the first option. J Neurosurg 2000;93:175-182

5. Ross IB, Dhillon GS. Balloon assistance as a routine adjunt to the endovascular treatment of cerebral aneurysms. Surg Neurol 2006;66:593-602

6. Pierot L, Spelle L, Leclerc X, Cognard C, Bonafe A, Moret J. Endovascular treatment of unruptured intracranial aneurysms: comparison of safety of remodeling technique and standard treatment with coils. Radiology 2009;251:846-855

7. Pierot L, Cognard C, Anxionnat R, Ricolfi F; for the CLARITY group. Remodeling technique for endovascular treatment of ruptured intracranial aneurysms had a higher rate of adequate postoperative occlusion than did conventional coil embolization with comparable safety. Radiology 2011;258:546-553

8. Pierot L, Cognard C, Spelle L, Moret J. Safety and efficacy of balloon remodeling technique during endovascular treatment of intracranial aneurysms: critical review of the literature. AJNR Am $J$ Neuroradiol 2012;33:12-15

9. Shapiro M, Babb J, Becske T, Nelson PK. Safety and efficacy of adjunctive balloon remodeling during endovascular treatment of intracranial aneurysms: a literature review. AJNR Am J Neuroradiol 2008;29:1777-1781

10. Rho MH, Kim BM, Suh SH, Kim DJ, Kim DI. Initial experience with the new double-lumen scepter balloon catheter for treatment of wide-necked aneurysms. Korean J Radiol 2013;14:832-840

11. Kim BM, Kim DJ, Kim DI. Stent application for the treatment of cerebral aneurysms. Neurointervention 2011;6:53-70

12. Chalouhi N, Jabbour P, Singhal S, Drueding R, Starke RM, Dalyai RT, et al. Stent-assisted coiling of intracranial aneurysms: predictors of complications, recanalization, and outcome in 508 cases. Stroke 2013;44L1348-1353

13. Jeon P, Kim BM, Kim DI, Park SI, Kim KH, Kim DJ, et al. Reconstructive endovascular treatment of fusiform or ultrawideneck circumferential aneurysms with multiple overlatpping Enterprise stents and coiling. AJNR Am J Neuroradiol 2012;33: 965-971

14. Collby GP, Paul AR, Radvany MG, Gandhi D, Gailloud P, Huang $\mathrm{J}$, et al. A single center comparison of coiling versus stent assisted coiling in 90 consecutive paraophthalmic region aneurysms. $J$ Neurointerv Surg 2012;4:116-120

15. Roy D, Milot G, Raymond J. Endovascular treatment of unruptured aneurysms. Stroke 2001;32:1998-2004 


\section{Keun Young Park, et al.}

16. Jeon P, Kim BM, Kim DJ, Kim DI, Suh SH. Treatment of multiple intracranial aneurysms with 1-stage coiling. AJNR Am J Neuroradiol 2014;35:1170-1173
17. Jeon HJ, Kim BM, Kim DJ, Park KY, Kim JW, Kim DI. Combination of multicatheter plus stent or balloon for treatment of complex aneurysms. AJNR Am J Neuroradiol 2016;37:311-316 